\title{
BMJ Open Assessment of drug use pattern using WHO core drug use indicators in selected general hospitals: a cross-sectional study in Tigray region, Ethiopia
}

\author{
Segen Gebremeskel Tassew, ${ }^{1}$ Haftom Niguse Abraha, ${ }^{1}$ Kidu Gidey (D) , ${ }^{1}$ \\ Abadi Kahsu Gebre (1) ${ }^{2}$
}

To cite: Tassew SG, Abraha HN, Gidey $\mathrm{K}$, et al. Assessment of drug use pattern using WHO core drug use indicators in selected general hospitals: a cross-sectional study in Tigray region, Ethiopia. BMJ Open 2021;11:e045805. doi:10.1136/ bmjopen-2020-045805

- Prepublication history for this paper is available online. To view these files, please visit the journal online (http://dx.doi org/10.1136/bmjopen-2020045805).

Received 14 0ctober 2020 Accepted 13 September 2021

D Check for updates

(C) Author(s) (or their employer(s)) 2021. Re-use permitted under CC BY-NC. No commercial re-use. See rights and permissions. Published by BMJ.

${ }^{1}$ Department of Clinical Pharmacy, Mekelle University College of Health Sciences, Mekelle, Ethiopia

${ }^{2}$ Department of Pharmacology and Clinical Toxicology, Mekelle University College Health Sciences, Mekelle, Ethiopia

Correspondence to Segen Gebremeskel Tassew; Segengm@gmail.com

\section{ABSTRACT}

Objective Inappropriate use of medicine is a global challenge with greater impact on developing countries. Assessment of drug use pattern is used to identify gaps in medicine utilisation to implement strategies for promoting rational drug use. This study aimed to assess drug use pattern using the WHO drug use indicators in selected general hospitals in Tigray region, Ethiopia.

Design A cross-sectional study was conducted using WHO drug use indicators in two public hospitals located in Tigray.

Setting Prescriptions recorded from 1 January 2017 to 1 June 2019 were randomly selected, and participants who visited the public hospitals from 1 March 2019 to 30 August 2019 and hospital pharmacies were interviewed. Participants 100 patients who visited both outpatient clinics and hospital pharmacy departments of the public hospitals.

Results The average number of medicines per prescription was $1.69( \pm 0.81)$. Prescriptions containing antibiotics and injectables were $58.2 \%$ and $15.9 \%$, respectively. The percentages of medicines prescribed with a generic name from essential medicines list of Ethiopia were $97.5 \%$ (974) and $88.1 \%(970)$ in Mekelle Hospital and Quiha Hospital, respectively. The patients spent an average of 6.6( \pm 3.5$)$ min with their general practitioners, while only $22.8( \pm 21.7)$ s with their pharmacists. Of the patients interviewed, 56.9\% knew their dosing regimen and $32.7 \%$ of them had their medication labelled. Conclusion The finding of the present study revealed deviation of drug use pattern from the WHO optimal levels suggesting the hospitals had limitations in appropriate utilisation of medicines. Understanding the factors attributed to the observed gaps and implementing corrective measures are required to conform with the recommended standards of appropriate drug utilisation.

\section{INTRODUCTION}

The rational use of drugs depends on rational prescribing, correct dispensing and adherence to treatment by patients. ${ }^{1}$ According to the WHO, a medicine is used rationally if patients received appropriate medicines, in doses that meet their individual requirements, for an adequate period of time and with an
Strengths and limitations of this study

- The study used all three of the WHO core drug use indicators to assess quality of patient care in a hospital setting

- Evidence about rational drug use has been provided in an area rarely assessed.

- The study did not try to identify the factors that contributed to the observed gaps making it difficult to propose improvement strategies.

- As diagnosis was missing in considerable number of prescriptions, we did not confirm that the drugs were prescribed for right diagnoses.

affordable cost. ${ }^{2}$ The concept of rational drug use can be summarised as the right medicine at the right dose by the right route at the right time for the right patient ('five rights'). ${ }^{3}$ Conversely, irrational use of medicines is termed to have occurred when one or more of the above-mentioned conditions are not met. ${ }^{2}$ Irrational use of medicine is a global challenge with the highest prevalence in developing countries. Multiple stakeholders including patients, prescribers, workplace and supply system may be attributed for irrational drug use ${ }^{4}$ due to many reasons such as limited knowledge about medicines, unethical medicine promotions and improper prescribing habits of clinicians. ${ }^{56}$

WHO drug use indicators are used to evaluate rational drug use at all levels in the chain of medicine utilisation (facility, clinician, pharmacist and patient) using highly standardised indicators developed by WHO Action Program on Essential Drugs and International Network for Rational Use of Drugs to be used for drug use evaluations without further national validation. ${ }^{78}$ Prescribing indicators include average number of medicines prescribed per encounter, percentage of those prescribed by generic name and 
those from national essential medicines list, percentage of encounters with antibiotics and those with injections prescribed. Patient care indicators are used to evaluate the interaction between the patients with their clinicians and pharmacists, and include average consultation and dispensing times, percentage of medicines dispensed and those adequately labelled, as well as patients' knowledge of correct dosage. The availability of the copy of essential medicines list and key medicines is assessed using facility indicators. $^{9}$

Ethiopia has introduced a national drug policy in 1993 with the aim of meeting the demand for essential medicines together with appropriate use, making them affordable to the public as well as ensuring their safety, efficacy and quality. The policy also encourages domestic manufacturing, enhancing manpower training and research and development of medicines as well as devising ways to integrate traditional medicines into conventional medicine as objectives. ${ }^{10}$ Despite these policy directions, studies conducted so far reported gaps in rational medicine use. ${ }^{11}{ }^{12}$ Considering the very large population size of Ethiopia and the diversity of geographical areas, there are very few studies on medicine use conducted so far. Therefore, this study was conducted to evaluate drug use and contribute to addressing the information gap in drug use pattern in Ethiopia, specifically Tigray region.

\section{METHODS AND MATERIALS}

\section{Study setting and period}

The study was conducted in Mekelle and Quiha General Hospitals between 1 March 2019 and 30 August 2019. Both hospitals are located in Mekelle, the capital city of Tigray regional state, Ethiopia.

\section{Study design and population}

All prescriptions recorded from 1 January 2017 to 1 June 2019 were considered. Of which, randomly selected prescriptions were retrospectively assessed using WHO prescribing indicators during the study period (1 March 2019 and 30 August 2019). All patients who visited outpatient departments of Mekelle and Quiha Hospitals during the study period were used as a target population. Of note, patients aged less than 18 years or not willing to participate in the study were excluded.

\section{Sampling technique and procedure}

The WHO recommends assessments of at least 600 prescriptions and 100 patients per each hospital for drug use evaluation. Accordingly, 600 randomly selected prescriptions recorded from 1 January 2017 to 1 June 2019 from each hospital were included. Twenty key drugs were also selected from each hospital as per WHO recommendation which is a minimum of 15 essential drugs for each health facility. ${ }^{9}$

\section{Data collection instruments and process}

Three well-trained pharmacists were recruited and deployed to assess the prescriptions identified using prescription registration books, interview patients, and evaluate availability of copy of essential medicines list and key medicines in the hospitals. Data on quality of prescribing were collected by using WHO's prescribing indicators. In assessing patient care indicators, the average number of medicines prescribed per encounter, the percentage of medicines prescribed with generic names and those prescribed from essential medicines list, the percentage of prescription encounters which ended up with antibiotics and those with injections prescribed were collected. However, immunisations of children were not considered as injections. In measuring the proportion of medicines prescribed with generic names, the essential medicines list of Ethiopia was used as a source for generic names. ${ }^{13}$

For assessment of patient care indicators, consultation time and dispensing time were obtained by recording the time that the patients spent with their physicians and pharmacists, respectively. The knowledge of the patients on their dosage regimen was assessed by asking the patients to explain whether they knew about the medicine dispensed to them. Availability of formulary, essential drugs, standard treatment guidelines, and key drugs at the time of the visit were assessed to confirm whether the hospitals comply with WHO standards.

\section{Operational definitions}

Drug use evaluation is a systematic approach that assesses the appropriateness, safety and effectiveness of a medication to improve patient care.

Percentage of drugs prescribed by generic name

It measures the tendency to prescribe by generic name.

Percentage of drugs prescribed from a list of essential drugs

It measures the degree to which practices conform to a national drug policy.

\section{Average number of drugs per encounter}

Average number of drugs per encounter measures the degree of polypharmacy.

\section{Average consultation time}

The average time that physicians spend with patients. It does not include waiting time.

\section{Average dispensing time}

The average time that pharmacists spend with patients while dispensing the medications.

\section{Data analysis procedure}

The data collected were entered and analysed using SPSS V.20. The data on prescribing indicators as well as patient care indicators were described using frequency, percentage, mean and SD. 
Table 1 Number of drugs per prescribing encounter in the selected general hospitals

\begin{tabular}{|c|c|c|c|c|}
\hline Number of drugs & $\begin{array}{l}\text { Quiha Hospital } \\
\text { n (\%) }\end{array}$ & $\begin{array}{l}\text { Mekelle Hospital } \\
\text { n (\%) }\end{array}$ & $\begin{array}{l}\text { Overall result } \\
\mathbf{N}(\%)\end{array}$ & WHO standard ${ }^{22}$ \\
\hline One & $306(51)$ & $286(47.7)$ & $592(49.7)$ & \\
\hline Three & $72(12)$ & $82(13.7)$ & $154(12.9)$ & \\
\hline Four & $15(2.5)$ & $17(2.8)$ & $32(23.5)$ & \\
\hline
\end{tabular}

\section{Patient and public involvement}

Patients and/or the public were not directly involved in this study.

\section{RESULTS}

\section{Prescribing indicators}

A total of 1200 prescriptions, 600 from each hospital, were evaluated using $\mathrm{WHO}$ prescribing indicators. On average, $1.69( \pm 0.81)$ drugs were prescribed and $44.7 \%$ of the prescriptions contain one or two drugs (table 1).

A total of 2028 drugs were prescribed, of which 1944 $(92.8 \%)$ were prescribed in generic name. More than $50 \%(58.2 \%)$ of the prescriptions contained antibiotics and $191(15.9 \%)$ include at least one injectable medication (table 2). Amoxicillin was the most frequently prescribed antibiotic in both hospitals (table 3 ).

\section{Patient care indicators}

On average, each patient spent approximately $7 \mathrm{~min}$ with his/her general practitioner and $22 \mathrm{~s}$ with his/her pharmacist. A total of $81.2 \%$ of the prescribed drugs were dispensed. Of which, $32.7 \%$ of them were adequately labelled. A total of $56.9 \%$ of patients knew about the dosage regimen of their medications (table 4).

\section{Health facility indicators}

Both Quiha and Mekelle Hospitals had their own formulary, essential drugs list and standard treatment guidelines. From the list of key drugs of the hospitals, on average, $77.5 \%$ of them were available in stock (table 5 ).

\section{DISCUSSION}

In this study, the average number of drugs per prescription was within the $\mathrm{WHO}$ acceptable standard. The finding was comparable with studies done in different parts of Ethiopia including Jimma (1.59) ${ }^{14}$ Hawassa University Teaching Referral (1.9) ${ }^{11}$ and Bahir Dar Hospital (1.8) ${ }^{12}$ However, studies in Debre Tabor (2.2), ${ }^{12}$ Felege Hiwot Referral Hospital $(2.49)^{15}$ and Karamara Public General Hospital in Ethiopia (2.46) ${ }^{16}$ reported higher average number of drugs per prescription. Such discrepancy may be attributable to differences in the level of awareness among clinicians working in different parts of the country and lack of harmonised national prescribing guidelines.

In terms of percentage of medicines prescribed by generic name, our finding is lower than the WHO's recommended standard value. Similar results were reported in Hawassa University Hospital $(98.7 \%),{ }^{11}$ Felege Hiwot Specialized University Hospital $(97.4 \%)^{15}$ and selected health centres in eastern Ethiopia $(97 \%) .{ }^{17}$ This may be attributable to increasing promotion of brand drugs names influencing clinicians to prescribe drugs in their brand names. Of note, Workneh et $a l^{18}$ have shown the prescribing decisions of clinicians working in Mekelle were influenced by promotion of medical representatives. This suggests that there is a gap in ensuring patients to get cost-effective medicines on the side of prescribers and the health institution, which in turn reduces healthseeking behaviour of the community. ${ }^{19}$

The percentage of encounters with antibiotics, which is $58.2 \%$ in the present study, is comparable with a

\begin{tabular}{|c|c|c|c|c|c|}
\hline \multicolumn{2}{|c|}{ Prescribing indicators } & \multirow{2}{*}{$\begin{array}{l}\text { Quiha Hospital } \\
999\end{array}$} & \multirow{2}{*}{$\begin{array}{l}\text { Mekelle Hospital } \\
1029\end{array}$} & \multirow{2}{*}{$\begin{array}{l}\text { Overall result (N) } \\
2028\end{array}$} & \multirow[t]{2}{*}{ WHO standard ${ }^{22}$} \\
\hline Generic prescription & Drugs prescribed, $\mathrm{n}$ & & & & \\
\hline Antibiotics & $\begin{array}{l}\text { Prescriptions with } \\
\text { antibiotics, n (\%) }\end{array}$ & $392(65.3)$ & $306(51)$ & $698(58.2)$ & $<30 \%(20-26.8)$ \\
\hline \multicolumn{2}{|c|}{ Drugs from essential drugs list, $\mathrm{n}(\%)$} & $974(97.5)$ & $930(90.4)$ & 1904 (93.9) & $100 \%$ \\
\hline
\end{tabular}


Table 3 Antimicrobial/antibiotics prescribed in the selected general hospitals

\begin{tabular}{|c|c|c|c|c|}
\hline \multirow{2}{*}{ Class of antimicrobial agen } & & \multicolumn{2}{|l|}{ Frequency, n } & \multirow[b]{2}{*}{ Overal } \\
\hline & & Quiha Hospital & Mekelle Hospital & \\
\hline \multirow[t]{17}{*}{ Antibacterial agents } & Amoxicillin & 160 & 76 & 236 \\
\hline & Ciprofloxacin & 56 & 44 & 100 \\
\hline & Ceftriaxone & 33 & 57 & 90 \\
\hline & Metronidazole & 42 & 40 & 82 \\
\hline & Cephalexin & 20 & 35 & 55 \\
\hline & Amoxicillin/clavulanic acid & 15 & 28 & 43 \\
\hline & Azithromycin & 19 & 16 & 35 \\
\hline & Cloxacillin & 21 & 11 & 32 \\
\hline & Norfloxacin & 17 & 11 & 28 \\
\hline & Sulfamethoxazole/trimethoprim & 13 & 11 & 24 \\
\hline & Doxycycline & 13 & 7 & 20 \\
\hline & Ampicillin & 1 & 9 & 10 \\
\hline & Clarithromycin & 8 & 1 & 9 \\
\hline & Erythromycin & 2 & 2 & 4 \\
\hline & Gentamycin & 1 & 2 & 3 \\
\hline & Ceftazidime & - & 2 & 2 \\
\hline & Crystalline penicillin & - & 1 & 1 \\
\hline \multirow[t]{5}{*}{ Antiprotozoal/anthelmintics } & Tinidazole & 14 & 17 & 31 \\
\hline & Albendazole & 16 & 7 & 23 \\
\hline & Mebendazole & 11 & 5 & 17 \\
\hline & Coarthem & 2 & - & 2 \\
\hline & Praziquantel & 1 & - & 1 \\
\hline \multirow[t]{3}{*}{ Antifungal } & Ketoconazole & 4 & - & 4 \\
\hline & Clotrimazole vaginal supp & 3 & - & 3 \\
\hline & Fluconazole & 1 & - & 1 \\
\hline Antiviral & Acyclovir & 2 & - & 2 \\
\hline
\end{tabular}

Amoxicillin or amoxicillin/clavulanic acid, and ceftriaxone were commonly prescribed antibiotics.

study conducted in public hospitals in eastern Ethiopia $(57.9 \%)^{16}$ and Hawassa Teaching Referral Hospital $(58.1 \%) .{ }^{11}$ As high as $85.5 \%$ were also reported in selected health centres in eastern Ethiopia. ${ }^{17}$ However, our finding is higher than the WHO recommended standard (20\%-26.8\%). This finding should be interpreted cautiously as high prevalence of infectious diseases in developing countries may partly contribute to such high antibiotic prescribing. However, overprescribing of antibiotics is a problem that needs to be carefully

Table 4 Assessment of patient care using WHO patient care indicators in selected general hospitals

\begin{tabular}{lllll}
\hline Patient care indicators & Quiha Hospital & Mekelle Hospital & Overall & WHO standard \\
\hline Average consultation time $(\mathrm{min})$ & $3.66 \pm 2.2$ & $9.5 \pm 4.8$ & $6.6 \pm 3.5$ & 10 \\
\hline Average dispensing time (s) & $21.5 \pm 19.9$ & $24.0 \pm 23.5$ & $22.8 \pm 21.7$ & $>180$ \\
Total number of drugs prescribed & 189 & 171 & 360 & \\
Total number of drugs dispensed & 170 & 124 & 294 & \\
Percentage of drugs actually dispensed & 89.9 & 72.5 & 81.2 & $100 \%$ \\
Number of drugs adequately labelled & 29 & 50 & 79 & \\
Percentage of drugs adequately labelled & 15.4 & 50 & 32.7 & \\
Knows dosage & $25(25 \%)$ & $48(88.8 \%)$ & 56.9 & \\
\hline
\end{tabular}


Table 5 Availability of key drugs in selected general hospitals

\begin{tabular}{|c|c|c|}
\hline List of key drugs & Quiha Hospital & Mekelle Hospital \\
\hline $\begin{array}{l}\text { Amoxicillin/clavulanic } \\
\text { acid }\end{array}$ & $\checkmark$ & $x$ \\
\hline Ciprofloxacin tablet & $\checkmark$ & $x$ \\
\hline Cloxacillin capsule & $\checkmark$ & $x$ \\
\hline Azithromycin & $\checkmark$ & $x$ \\
\hline Diclofenac injection & $\checkmark$ & $\checkmark$ \\
\hline Diclofenac tablet & $\checkmark$ & $\checkmark$ \\
\hline Tramadol & $x$ & $\checkmark$ \\
\hline Metronidazole & $\checkmark$ & $\checkmark$ \\
\hline Insulin & $\checkmark$ & $\checkmark$ \\
\hline Nifedipine & $x$ & $\checkmark$ \\
\hline Lasix & $x$ & $\checkmark$ \\
\hline Spironolactone & $\mathrm{x}$ & $\checkmark$ \\
\hline Ceftriaxone & $\checkmark$ & $x$ \\
\hline Vancomycin & $\checkmark$ & $\checkmark$ \\
\hline Metformin & $\checkmark$ & $\checkmark$ \\
\hline Enalapril & $\checkmark$ & $\checkmark$ \\
\hline Cephalexin & $\checkmark$ & $\checkmark$ \\
\hline Ferrous sulfate & $\checkmark$ & $\checkmark$ \\
\hline Paracetamol syrup & $\checkmark$ & $x$ \\
\hline Amlodipine & $\checkmark$ & $\mathrm{X}$ \\
\hline
\end{tabular}

monitored as it is associated with antimicrobial resistance which is a threat to global health. ${ }^{20}$ The percentage of prescription encounters with injections was within the WHO standard level.

The WHO recommends healthcare professionals to adhere to national essential medicines list for drug prescribing. To this end, a deficiency was noted in terms of prescribing according to essential medicines list of Ethiopia compared with the WHO standard of a $100 \%{ }^{8}$ and to that of the national assessment results of 2003 $(99 \%) .{ }^{21}$ This may be attributable to patient preference, clinician decision and availability of the medications.

In this study, the average consultation time that the patients spent with clinicians was approximately $7 \mathrm{~min}$, which is higher compared with studies conducted in public hospitals in eastern Ethiopia $(4.6 \mathrm{~min}) .{ }^{16}$ The duration, however, does not seem to be sufficient to make physical examination and select the best available treatment choices. High patient load could have contributed to such below optimal duration of consultation time. The average dispensing time recorded in the present study was approximately $23 \mathrm{~s}$. This is significantly lower than the WHO recommendation of $180 \mathrm{~s}^{8}$ The lower the dispensing time, the poorer the understanding of the patients would be about their medications, which may lead to frequent encounters of drug therapy problems.
The percentage of drugs actually dispensed out of the total drugs prescribed to the patients stood at $80 \%$ compared with the recommended $100 \%{ }^{6}$ Frequent stock out of medicines may account for this finding. Regarding the adequacy of labelling of medicines dispensed, slightly over one-third of medicines were appropriately labelled, which is far from the recommended level of $100 \%{ }^{8}$ High patient load encountered at an outpatient pharmacy department and negligence of the pharmacists together with poor concern and follow-up from the hospital side could be implicated for such low level of performance in this indicator. Of note, only about half of the patients knew the dosage schedules of medicines prescribed to them, which is far below the expected level of $100 \%$.

Both Quiha and Mekelle Hospitals had their own essential drugs list and standard treatment guidelines. Only $7.5 \%$ of key drugs were in stock and this is lower than the $100 \%$ of the WHO recommendation. Absence of key drugs may impair patient care and compromise patient quality of life.

\section{CONCLUSION}

The findings of the present study showed prescribing practices of antibiotics, prescribing from essential drugs list and injections were not within the acceptable WHO recommendations. Overuse of antibiotics facilitates the emergence of antimicrobial resistance which is a threat to global health. There was a little deviation in terms of generic prescribing, whereas the average number of drugs per encounter was within the acceptable standard. Poor generic prescribing coupled with shorter consultation and dispensing time may lead to frequent encounters of drug therapy problems. Future studies should investigate underlying factors that contributed to the observed gaps to improve patient care in those hospitals.

Acknowledgements The authors wish to thank all the staff members of Mekelle and Quiha Hospitals for their sincere cooperation and support.

Contributors SGT and AKG designed the study, obtained the fund, supervised data collection, conducted data analysis and wrote the first draft of the manuscript. SGT, $\mathrm{KG}, \mathrm{AKG}$ and HNA provided critical comments, revised and finalised the manuscript. All authors read and approved the final manuscript.

Funding This study was funded by College of Health Sciences, Mekelle University small scale grant with registration number of $\mathrm{CRPO} / \mathrm{CHS} /$ Young/Recurrent/ 008/2011.

\section{Competing interests None declared.}

Patient and public involvement Patients and/or the public were not involved in the design, or conduct, or reporting, or dissemination plans of this research.

\section{Patient consent for publication Not required.}

Ethics approval The study was approved by the Institutional Review Board of Mekelle University (reference number: ERC/224/2019). Based on this, a letter of support was written from Tigray regional health bureau. During data collection on patient care indicators, a written consent was obtained from each participant after provision of all the necessary information. In addition, the data collected in the study did not use patient identifiers and were kept strictly confidential and were only used for the purpose of the study.

Provenance and peer review Not commissioned; externally peer reviewed.

Data availability statement Data are available upon reasonable request. The data of this study are available from the corresponding author upon reasonable request. 
Open access This is an open access article distributed in accordance with the Creative Commons Attribution Non Commercial (CC BY-NC 4.0) license, which permits others to distribute, remix, adapt, build upon this work non-commercially, and license their derivative works on different terms, provided the original work is properly cited, appropriate credit is given, any changes made indicated, and the use is non-commercial. See: http://creativecommons.org/licenses/by-nc/4.0/.

\section{ORCID iDs}

Kidu Gidey http://orcid.org/0000-0002-7363-1327

Abadi Kahsu Gebre http://orcid.org/0000-0002-1975-0085

\section{REFERENCES}

1 Timmermans A, Sharma A. Rational use of drugs. In: United nations high commissioner for refugees. Drug management manual. Refugees UNHCf, 2006: 87-104.

2 WHO. The pursuit of responsible use of medicines: sharing and learning from country experiences. World Health Organization, 2012.

3 Mehta S, Gogtay NJ. From the pen to the patient: minimising medication errors. J Postgrad Med 2005;51:3.

4 Chaturvedi VP, Mathur AG, Anand AC. Rational drug use - as common as common sense? Med J Armed Forces India 2012;68:206-8.

5 De Vries T, Henning RH, Hogerzeil HV. Guide to good prescribing: a practical manual. World Health Organization, 1994.

6 Ramsay LE. Bridging the gap between clinical pharmacology and rational drug prescribing. Br J Clin Pharmacol 1993;35:576.

7 Dukes MNG. Drug utilization studies: methods and uses. World Health Organization. Regional Office for Europe, 1993.

8 WHO. How to investigate drug use in health facilities: selected drug use indicators. World Health Organization, 1993.

9 WHO. Promoting rational use of medicines: core components. World Health Organization, 2002.
10 National drug Policy of the Trational. Government of Ethiopia, 1993.

11 Desalegn AA. Assessment of drug use pattern using WHO prescribing indicators at Hawassa university teaching and referral hospital, South Ethiopia: a cross-sectional study. BMC Health Serv Res 2013;13:1-6.

12 Desta Z, Abula T, Gebre-Yohannes A, et al. Drug prescribing patterns for outpatients in three hospitals in north-west Ethiopia. Ethiopian Journal of Health Development 2002;16:183-9.

13 FMHACA. List of essential medicines for Ethiopia, 2010.

14 Abdulahi M, Shiferaw T. Patterns of prescription in Jimma Hospital. Ethiop J Health Dev 1997;11.

15 Laychiluh B. Assessment of drug prescription practice using who prescribing indicators in felege hiwot referral hospital (FHRH) outpatient department, North, Ethiopia. Int J Pharm 2014;4:89-94.

16 Sisay M, Mengistu G, Molla B, et al. Evaluation of rational drug use based on world health organization core drug use indicators in selected public hospitals of Eastern Ethiopia: a cross sectional study. BMC Health Serv Res 2017;17:1-9.

17 Bilal Al, Osman ED, Mulugeta A. Assessment of medicines use pattern using world health organization's prescribing, patient care and health facility indicators in selected health facilities in Eastern Ethiopia. BMC Health Serv Res 2016;16:1-8.

18 Workneh BD, Gebrehiwot MG, Bayo TA, et al. Influence of medical representatives on prescribing practices in Mekelle, Northern Ethiopia. PLoS One 2016;11:e0156795.

19 Shaikh BT, Hatcher J. Health seeking behaviour and health service utilization in Pakistan: challenging the policy makers. J Public Health 2005;27:49-54.

20 Llor C, Bjerrum L. Antimicrobial resistance: risk associated with antibiotic overuse and initiatives to reduce the problem. Ther Adv Drug Saf 2014;5:229-41.

21 WHO. Assessment of the pharmaceutical sector in Ethiopia: Addis Ababa. Ethiopia: Ministry of Health, 2003.

22 Isah AO, Laing R, Quick J, et al. The development of reference values for the who health facility core prescribing indicators. West Afr $J$ Pharmacol Drug Res 2001;18:6-11. 